\title{
A imigração na sala de aula: uma análise sobre a convivência entre diferentes
}

\author{
Joziane Ferraz de Assis ${ }^{1}$ \\ Thaiana Oliveira Dias ${ }^{2}$
}

Resumo: O presente artigo é parte de uma pesquisa de Iniciação Científica financiada pelo Conselho Nacional de Desenvolvimento Científico e Tecnológico (CNPQ) através do Programa PIBIC/UFV ${ }^{3}$, e buscou analisar, a partir da perspectiva intercultural, como se deram a convivência e as trocas linguísticas e culturais entre um aluno venezuelano e seus colegas e professores em uma escola da cidade de Viçosa/Minas Gerais. Para isso, fez-se uma extensa pesquisa bibliográfica baseando-se em autores como Assis (2018), Freire (2011), Paraquett (2010) e Goenechea (2008), observou-se a realidade escolar com anotações em cadernos de campo e aplicaram-se questionários tanto ao aluno venezuelano quanto aos seus colegas e professores brasileiros, tratando-se, portanto, de uma pesquisa qualitativa, descritiva e interpretativista. A partir das análises dos dados, identificou-se uma constante exclusão do aluno estrangeiro, visto que os brasileiros pouco se comunicavam com ele, bem como a dificuldade das professoras participantes em atuar nas distintas situações que esse contexto apresenta. No presente artigo, apresentaremos os resultados da pesquisa na categoria de análise "convivência", refletindo sobre a imigração, a presença de alunos estrangeiros em sala de aula e a formação de professores.

Palavras Chave: interculturalidade, imigração, formação de professores, espanhol língua estrangeira.

\section{Introdução}

O presente artigo é um recorte de uma pesquisa de Iniciação Científica intitulada “ $A$ escola viçosense e as experiências de imigração venezuelana: questões linguístico-culturais de uma nova demanda", desenvolvida em uma escola municipal da cidade de Viçosa/MG

\footnotetext{
${ }^{1}$ Professora de Língua Espanhola na Universidade Federal de Viçosa. Doutora em Língua e Cultura pela Universidade Federalda Bahia.E-mail: joziane.assis@ufv.br

${ }^{2}$ Professora de Lingua Portuguesa na rede estadual de ensino na cidade de Viçosa/MG. Graduada em Letras PortuguêsEspanhol pela Universidade Federal de Viçosa.E-mail: thaiana.dias@ufv.br

${ }^{3}$ Agradecemos ao CNPQ pelo financiamento da pesquisa.
}

Gláuks: Revista de Letras e Artes-jan/jun. 2020 - Vol. 20, $N^{o} 1$ 
com bolsa de pesquisa financiada pelo CNPQ por meio do Programa Institucional de Bolsas de Iniciação Científica da Universidade Federal de Viçosa - PIBIC/UFV. A investigação se apoiou nos conceitos e princípios da interculturalidade, buscando compreender como se davam as relações linguísticas e culturais entre um estudante/imigrante venezuelano, recémchegado à escola, e seus colegas e professores brasileiros.

Desse modo, a pergunta de pesquisa referente ao trabalho foi a seguinte: "Como convive e se intercomunica o aluno venezuelano da escola nas relações com os brasileiros em ambiente escolar e quais são as demandas percebidas pela escola e pelos próprios estudantes para aperfeiçoar tais relações?”. Para obter tais respostas, fez-se um estudo bibliográfico sobre os temas que circundam a imigração, a interculturalidade e a formação de professores, observou-se um total de 6 dias de aulas no período integral na escola no ano de 2018, com anotações em cadernos de campo e, ao final das observações, foram aplicados questionários tanto ao corpo docente e discente brasileiros, quanto ao estudante estrangeiro. Da totalidade de questionários distribuídos na escola, obtivemos o retorno de 8 estudantes brasileiros e 3 professoras, além do próprio estudante venezuelano. A pesquisa contou com aprovação do Comitê de Ética na Pesquisa com Seres Humanos da UFV.

Neste artigo analisaremos uma das categorias delimitadas pela pesquisa, denominada "convivência", visto que se buscou compreender como se deu o convívio entre os alunos e professores brasileiros e o venezuelano a partir das interações linguísticas e sociais entre eles. Igualmente refletiremos sobre a imigração e a presença de alunos estrangeiros em sala de aula e a formação de professores. Iniciaremos, porém, apresentando brevemente o referencial que nos guiou nos estudos teóricos e na análise dos dados gerados.

\section{Formação de professores na perspectiva intercultural e imigração}

Iniciamos esta seção apresentando sucintamente como entendemos a interculturalidade. Partimos de Paraquett (2010), que caracteriza a interculturalidade em

Gláuks: Revista de Letras e Artes-jan/jun. 2020 - Vol. 20, $N^{o} 1$ 
diferenciação a outros conceitos do campo da cultura, quais sejam, o multiculturalismo, o pluriculturalismo e o transculturalismo. É o que se lê abaixo:

\begin{abstract}
O Multiculturalismo é determinado pela co-presença de várias culturas num espaço concreto, mas cada um com seu estilo e modos de vida diferentes. Quando se fala em Pluricultural também há a co-presença de várias culturas, mas sem que haja a convivência entre elas. Ao contrário, ressalta-se a diversidade. Também há o termo Transcultural. Mas, neste caso, trata-se de um movimento de uma cultura em direção à outra, sugerindo a aceitação do outro e de seus referentes culturais, sem discriminação, sem preconceito. Por fim, entende-se por Interculturalidade a interrelação ativa e a interdependência de várias culturas que vivem em um mesmo espaço geográfico (PARAQUETT, 2010, p. 144).
\end{abstract}

Levando-se em consideração que a vivência da interculturalidade é uma via de mão dupla, na qual todas as pessoas em contato são recíprocas, aprendem entre si, além de compartilharem experiências, pressupõe-se que, nessa perspectiva, os indivíduos apresentam maior respeito e aceitação pelo outro. Como nosso campo de interesse é a educação, faz-se necessário refletir também sobre o que é ser um professor intercultural. Para isso, torna-se importante pensar a formação de professores na licenciatura e sobre como a formação docente se reflete na escola, consequentemente, nas relações que se criam e se estabelecem entre o corpo docente e discente nesse ambiente. Pode-se começar a pensar com Paulo Freire (2011, p. 24), para quem:

Se, na experiência de minha formação, que deve ser permanente, começo por aceitar que o formador é o sujeito em relação a quem me considero o objeto, que ele é o sujeito que me forma e eu, o objeto por ele formado, me considero como um paciente que recebe os conhecimentos - conteúdos - acumulados pelo sujeito que sabe e que são a mim transferidos. Nesta forma de compreender e de viver o 
processo formador, eu, objeto agora, terei a possibilidade, amanhã, de me tornar o falso sujeito da "formação" do futuro objeto de meu ato formador (FREIRE, 2011, p. 24).

A partir do que disse o autor, se o professor, em seu próprio processo de formação, considera-se como objeto daquele que lhe transmite informações, acreditando na presença de um indivíduo ativo e outro passivo no processo de aprendizagem, ele não se baseia em uma perspectiva intercultural, já que, desse ponto de vista, todos fazem parte do processo de ensino-aprendizagem. Portanto, pode-se refletir sobre a seguinte pergunta: Temos uma formação nas universidades que nos propicie ser professores interculturais?

$\mathrm{O}$ que se pode concluir com relação a este questionamento, tomando como referência a experiência das autoras deste artigo, é que, ainda hoje, se observa uma formação universitária muito tradicional, e consequentemente, isso se reflete na escola quando os docentes lá chegam para ministrar suas aulas. Se a interculturalidade fosse um aspecto mais presente na formação de professores, se chegaria facilmente à conclusão de que "[...] quem forma se forma e reforma ao formar e quem é formado forma-se e forma ao ser formado" (FREIRE, 2011, p. 25) e que "Quem ensina aprende ao ensinar e quem aprende ensina ao aprender" (op. cit., p. 25).

Se a base educacional de formação de professores fosse intercultural, a diversidade provavelmente seria um tema mais presente dentro de sala de aula, e esse espaço não seria pensado como um lugar homogêneo, onde supostamente todos possuem as mesmas vivências prévias. Segundo Goenechea (2008, p.120), “[...] actualmente los profesionales de la educación reciben una formación que les capacita fundamentalmente para trabajar en una sociedad culturalmente homogénea $[\ldots]^{\prime 4}$.

Por isso, na escola em que foi realizada essa pesquisa, como aparecerá nas discussões a partir da análise dos dados, a maioria dos professores ministraram suas aulas como se ali estivessem somente brasileiros, porque lhes faltavam o conhecimento e a experiência sobre como lidar com diferentes nacionalidades na escola. Goenechea (2008, p. 129) diz que "[...] el profesorado no está preparado para trabajar en contextos multiculturales"s. E complementa

\footnotetext{
4 "Atualmente os profissionais da educação recebem formação que lhes capacita fundamentalmente para trabalhar em uma sociedade culturalmente homogênea [...]” (Essa e as demais traduções foram feitas pelas autoras deste artigo).

5 "[...] os professores não estão preparados para trabalhar em contextos multiculturais".
}

Gláuks: Revista de Letras e Artes-jan/jun. 2020 -Vol. 20, $N^{o} 1$ 
dizendo que "[...] no están preparados. Primero porque no han tenido una formación, pero es que la formación no es la panacea. En el fondo vivimos en una sociedad que no está preparada para la interculturalidad" ${ }^{\prime \prime}$ (op. cit., p. 129). Desse modo, percebe-se que a autora não só responsabiliza a falta de formação por parte do professorado, como também a sociedade como um todo, visto que a escola e a universidade fazem parte dela.

Pensando nisso, Goenechea (2008), em sua pesquisa, detecta que os professores têm uma base educacional muito pouco intercultural nas universidades, especialmente pensando na faixa etária desses profissionais, já que a perspectiva intercultural é uma discussão muito recente, tendo ganhado fôlego nos últimos anos do século XX, e a maior parte dos professores se formaram antes de se começar a discutir a interculturalidade no contexto escolar.

A autora diz que "[...] la presencia de alumnos extranjeros es hoy en día una realidad cotidiana en la mayor parte de España"7 (GOENECHEA, 2008, p. 119), afirmação que podemos estender facilmente ao Brasil, dado o trânsito constante de cidadãos entre os países. Então, “[...] ante esta realidad resulta obvio que el profesorado del siglo XXI requiere una formación específica para poder desarrollar adecuadamente su labor educativa en un contexto multicultural"8. Caso não tenha uma formação adequada, pode acontecer de os professores relacionarem "[...] la presencia de alumnos extranjeros con un problema y es a raíz de la existencia de esa situación problemática cuando el profesorado busca o demanda formación sobre el tema"9 (op. cit. p. 125).

Goenechea (2014), em outra pesquisa, identificou que "[...] docentes especialmente sensibilizados con la importancia de la lengua como elemento de la identidad cultural del alumno, tratan de aprender las lenguas maternas de sus alumnos y las usan [...] en clase"10 (GOENECHEA, 2014, p. 1069). Buscar aprender um pouco a língua desse aluno imigrante, com o intuito de incluí-lo, também pode ser uma alternativa eficaz para o desenvolvimento

\footnotetext{
“[...] não estão preparados. Primeiro porque não tiveram uma formação, mas a formação não é a desculpa. No fundo vivemos em uma sociedade que não está preparada para a interculturalidade".

7 "[...] a presença de alunos estrangeiros hoje em dia é uma realidade cotidiana na maior parte da Espanha".

8 “[...] diante dessa realidade parece óbvio que os professores do século XXI requerem uma formação especifica para poder desenvolver adequadamente seu trabalho educativo em um contexto multicultural".

9 "[...] a presença de alunos estrangeiros a um problema e é por essa situação problemática que os professores buscam ou demandam uma formação sobre o tema".

10 “....] docentes especialmente sensibilizados com a importância da língua como elemento da identidade cultural do aluno, procuram aprender as línguas maternas de seus alunos e as usam [...] em sala de aula".
}

Gláuks: Revista de Letras e Artes-jan/jun. 2020 - Vol. 20, $N^{o} 1$ 
dos processos de ensino e aprendizagem nesse contexto. Segundo Freire (2011, p. 43), "mal se imagina o que pode passar a representar na vida de um aluno um simples gesto do professor. O que pode um gesto aparentemente insignificante valer como força formadora $[\ldots] "$.

A partir disso, se pode depreender que, de acordo com essas demandas dentro das escolas, o professorado precisa se adaptar às novas realidades e saber como lidar com a presença de alunos imigrantes no contexto escolar. Se a experiência da pesquisa aqui relatada, com apenas um aluno imigrante na sala de aula já demonstrou dificuldades do corpo docente para lidar com a questão, uma classe com mais alunos de outras nacionalidades representaria desafios ainda maiores.

Goenechea (2008) faz algumas perguntas fundamentais para reanalisarmos nossas práticas pedagógicas pensando em um contexto intercultural e, a partir dessas perguntas, pode-se refletir sobre a importância de analisar o espaço onde o educador está inserido, pois "há uma pedagogicidade indiscutível na materialidade do espaço" (FREIRE, 2011 p. 45). Ainda segundo Goenechea (2008), a fim de encontrar as possíveis medidas que devem ser tomadas para a integração de todos os educandos no espaço, devem-se fazer perguntas como:

\footnotetext{
¿Qué se entiende exactamente en la práctica por "formación en educación intercultural"? ¿Qué temáticas concretas abarcan estos cursos? ¿Con qué metodologías suelen trabajarse? Son preguntas que aún están por responder en gran medida y cuyas respuestas pueden encontrarse observando qué ocurre en la realidad $^{11}$ (GOENECHEA, 2008, p. 121).
}

Em nossa pesquisa, verificou-se que o aluno venezuelano era muito mais participativo nas aulas em que os professores tinham essa sensibilidade de perceber sua realidade, que tentavam falar em espanhol, que demonstravam preocupação em relação a sua participação 11 "O que se entende exatamente, na prática, por "formação em educação intercultural”? Que temáticas concretas esses
cursos abordam? Com qual metodologias costumam trabalhar? São perguntas que ainda se estão por ser respondidas e
cujas respostas podem ser encontradas observando o que ocorre na realidade". Gláuks: Revista de Letras e Artes-jan/jun. 2020 - Vol. 20, $N^{o} 1$ 
nas aulas. "Por isso é que, na formação permanente dos professores, o momento fundamental é o da reflexão crítica sobre a prática. É pensando criticamente a prática de hoje ou de ontem que se pode melhorar a próxima prática" (FREIRE, 2011 p. 40).

Caso contrário, se não se respeita a cultura de origem do aluno, este poderá criar resistências ao se relacionar com a nova cultura e com o novo espaço no qual está inserido. Por isso, Goenechea (2014, p. 1066) se pergunta “[...] si nuestro sistema educativo contribuye a formar identidades culturales equilibradas, manteniendo el alumno su cultura de origen; o si [...] promueve inexorablemente la asimilación como única vía de adaptación a la escuela" ${ }^{12}$.

Incluir um aluno imigrante em um determinado espaço não significa a exclusão total de suas vivências anteriores, muito menos o apagamento de sua cultura e costumes. Dentro de sala de aula, inclusão significa o compartilhamento e valorização de toda a diversidade presente. A interculturalidade nos contextos de imigração pode ser vista ainda como uma oportunidade para ampliar os campos de atuação do professor. Segundo Assis (2018, p. 184185):

\footnotetext{
Em uma perspectiva linguística ou linguístico-pedagógica, o contato entre o Espanhol e o Português, nesses contextos de imigração de hispano-falantes no Brasil, abre portas para uma série de consequências ao professor dessas línguas, como ensino de Português para falantes de Espanhol, ampliação do ensino de Espanhol para brasileiros, ganho de visibilidade dos venezuelanos entre os brasileiros e questões linguístico-formais próprias do contato entre as duas línguas-culturas (ASSIS, 2018, p. 184-185).
}

Ademais, muitos professores têm a percepção de que a necessidade de os alunos de escola pública aprenderem uma língua estrangeira é questionável, haja vista que estes possuem baixíssimas probabilidades de viajar ao exterior devido a sua situação socioeconômica. Assis (2018) observa que:

\footnotetext{
12 "[...] se o nosso sistema educativo contribui para formar identidades culturais equilibradas, mantendo o aluno em sua cultura de origem; ou [...] promove inexoravelmente a assimilação como via única de adaptação na escola".
} 
esse desmerecimento do ensino de línguas na escola é bastante perceptível para professores e alunos, já que ouvimos, repetidas vezes, que "não adianta aprender Inglês ou Espanhol porque nunca se sairá do país" ou "para que aprender uma língua estrangeira se nem Português os alunos sabem falar?” (ASSIS, 2018, p. 21).

Porém, ainda que muitos alunos brasileiros não tenham a possibilidade de viajar ao exterior a fim de entrar em contato com a língua estrangeira, podem ter contato com o estrangeiro em seu próprio país. É fato que aprender uma língua estrangeira está além da finalidade de viagem. Quando se aprende outra língua, pode-se aumentar o leque de conhecimento cultural, tendo acesso a mais informações, além de se ampliar a capacidade intelectual. Por esse motivo, ter acesso a línguas estrangeiras é uma questão de direito e políticas públicas e faz parte também da perspectiva política que adotamos no trabalho de pesquisa aqui apresentado.

Por fim, depreende-se que todos esses debates circundam a formação de professores na perspectiva da interculturalidade e "[...] si la formación del profesorado puede ser la clave de la educación intercultural, si consigue ponerla en marcha, ésta puede ser a su vez la raíz de una sociedad mejor en la que diversidad y convivencia vayan ineludiblemente unidas"13 (GOENECHEA, 2008, p. 134). Ou seja, se a formação de professores consegue caminhar rumo à interculturalidade, caminharemos também rumo a uma sociedade mais justa e menos desigual e excludente.

Importante ressaltar como o estudo bibliográfico da perspectiva intercultural foi importante para as pesquisadoras deste projeto a fim de desenvolver a pesquisa ora relatada, haja vista o necessário cuidado ético ao observar a sala de aula e se relacionar com as diferenças presentes naquele ambiente. Partimos, a seguir, para a análise dos dados gerados com os questionários e os cadernos de campo.

\footnotetext{
13 "[...] se a formação dos professores pode ser a chave da educação intercultural, se consegue implementá-la, essa pode ser a origem de uma sociedade melhor em que a diversidade e a convivência andam inevitavelmente unidas".
}

Gláuks: Revista de Letras e Artes-jan/jun. 2020 -Vol. 20, $N^{o} 1$ 


\section{A categoria "convivência"}

Nesta seção, serão analisadas as respostas aos questionários dos alunos e professoras brasileiras e do estudante venezuelano, bem como as anotações dos cadernos de campo das pesquisadoras, privilegiando a categoria "convivência". Ao longo da pesquisa, também analisamos as categorias "intercomunicação" e "demandas", entretanto, devido ao limite de páginas deste artigo, não trataremos das duas últimas.

Durante todo o desenvolvimento do estudo, tivemos uma terceira pesquisadoraparticipante, voluntária, que acompanhou todos os trabalhos, e cujas anotações serão consideradas neste artigo, juntamente com as anotações de uma de suas autoras. Dessa forma, identificaremos as pesquisadoras como PE1 e PE2. A fim de manter o anonimato de todos os envolvidos na pesquisa, os alunos brasileiros serão tratados como ' $\mathrm{A}$ ', o venezuelano como ' $\mathrm{V}$ ' e as professoras brasileiras como ' $\mathrm{P}$ '. Com o intuito de diferenciá-los entre si, todos virão seguidos com um número.

Importante ressaltar que a metodologia de análise dos dados consistiu em análise de conteúdo, com enumeração de recorrências lexicais e identificação de temas presentes nos cadernos de campo, e transcrição das respostas e enumeração das recorrências lexicais nos questionários, o que permitiu a definição das categorias de análise. A seguir, procedeu-se à triangulação dos dados gerados pelos questionários e pelos cadernos de campo, resultando nas análises dispostas adiante em relação à categoria "convivência".

Primeiramente, analisaram-se os questionários respondidos pelos alunos e, para a pergunta primeira - "Para você, como é conviver com um falante de espanhol na escola que não é fluente em português? Por quê?", percebeu-se que, de 8 alunos brasileiros participantes, 5 relataram que a convivência entre eles e o aluno venezuelano era "normal". Já para a segunda pergunta - "Como está sendo o processo de estudar (ou trabalhar) com um aluno que ainda está em adaptação à língua portuguesa?", houve respostas do tipo "Não vejo muita

\section{Gláuks: Revista de Letras e Artes-jan/jun. 2020 - Vol. 20, $N^{o} 1$}


diferença"14 (A1), ou que " Tá sendo meio difícil" (A3) e que "É um pouco difícil" (A8), e até mesmo um aluno como o A2 que reafirmou que a convivência entre eles era "normal".

O conceito de "normal" aqui pode ser entendido de maneira relativa, pois, a partir dessa resposta, podemos depreender que, para esse grupo, é "normal" não conversar com o aluno estrangeiro e que eles não sentem necessidade de dialogar com o mesmo, tornando comprometida a convivência entre essas pessoas. Para os que relataram certa dificuldade na convivência com o aluno venezuelano, pode-se depreender a dificuldade encontrada em se relacionar com pessoas provenientes de culturas diferentes ou a impossibilidade de conversar entre si.

Por outro lado, ainda em relação à primeira pergunta, 3 alunos brasileiros deram respostas positivas, dizendo que a convivência entre ambos é "muito legal" (A5), "muito interessante" (A6) e "bom" (A8). Tais alunos complementaram dizendo que "do mesmo jeito que a gente pode aprender com ele, ele aprende com nós" (A5), ou "dá pra aprender algumas palavras em espanhol" (A8).

Com relação à segunda questão, os alunos A4, A6, e A7 relatam que a convivência entre os mesmos é "Tranquilo", ou que "Está sendo legal" e até mesmo que "Está sendo bom". Podemos perceber que esses alunos se aproximam mais dos princípios da interculturalidade e do que seria uma convivência intercultural, porque reconhecem nesse contato uma possibilidade de trocas culturais e linguísticas. Como afirma Assis (2018):

Ora, se parto do meu próprio mundo para conhecer o mundo do outro, estou conhecendo-me e reconhecendo-me primeiro, processo no qual pode surgir a valorização de minha cultura, a descentralização de pontos de vista e a promoção do diálogo cultural que, embora conflitivo por vezes, favorece o crescimento individual e coletivo (ASSIS, 2018 p. 169).

\footnotetext{
${ }^{14}$ Optamos por manter as respostas e anotações originais dos participantes da pesquisa como constavam nos questionários e cadernos de campo.
}

Gláuks: Revista de Letras e Artes-jan/jun. 2020 -Vol. 20, $N^{o} 1$ 
Como a presença de alunos estrangeiros é cada vez mais um fato nas escolas devido às diásporas mundiais, essa experiência pode ser aproveitada como uma oportunidade para que os alunos brasileiros se conheçam melhor a partir do momento que se relacionam com alunos estrangeiros, o que pode se tornar uma experiência riquíssima, principalmente no ambiente escolar. Segundo Freire (2011):

Um dos saberes primeiros, indispensáveis a quem, chegando a favelas ou a realidades marcadas pela traição a nosso direito de ser, pretende que sua presença se vá tornando convivência, que seu estar no contexto vá virando estar com ele, é o saber do futuro como problema e não como inexorabilidade (FREIRE, 2011, p. 74).

Portanto, para o autor, há que se aprender a conviver com as diferenças quando estão dispostas diante de nós. Quando questionamos ao aluno venezuelano se ele se sentia integrado no ambiente escolar - "Pergunta 4. ¿En qué momentos te sientes integrado en la escuela? Y ¿en qué momentos no? ¿Por qué?"15, ele respondeu que "Yo me siento integrado la mayor parte del tiempo en realidad no sé por qué"16. Comparando-se essa resposta com as anotações do caderno de campo das pesquisadoras, essa integração parece não ter sido observada. As pesquisadoras relataram algumas vezes uma possível introspecção desse aluno, como expressou PE1 ao transcrever a fala de uma professora, que disse que "a introspecção provavelmente era uma característica pessoal [...] deste aluno".

E também em outro momento em que PE1 se questionou, e posteriormente, narrou por meio de suas anotações, quando "[...] lhe perguntei porque ele estava sozinho e ele me respondeu: "Siempre estoy solo"17. E disse que isso não é um problema para ele e que ele não se importa. A pergunta é: Ele quer interagir com os demais?” Porém, ainda através do caderno de campo, constatamos diversas vezes, assim como os dados gerados pelos questionários, que os brasileiros interagiam muito bem entre si, mas que o venezuelano estava realmente exposto a uma constante exclusão pelos demais.

\footnotetext{
15 "Em que momentos você se sente integrado na escola? Em que momentos não? Por quê?"

16 “Eu me sinto integrado na maior parte do tempo, mas na verdade eu não sei porquê".

17 'Sempre estou sozinho'.
}

Gláuks: Revista de Letras e Artes-jan/jun. 2020 - Vol. 20, $N^{o} 1$ 
PE1 relata o entrosamento observado entre os alunos brasileiros no seguinte trecho: "Pude perceber que os alunos mantem uma boa convivência entre eles, visto que os mesmos conversam muito e a todo momento". No entanto relata a exclusão do aluno venezuelano quando anota que "A maioria dos alunos conversa com algum colega do lado". E complementa dizendo que apenas o venezuelano “[...] não conversa com ninguém”.

Igualmente PE2 relata em suas anotações esse frequente afastamento do aluno venezuelano quando escreve que "Até o momento não havia sido observada nenhuma interação do garoto com o restante da sala, que a todo momento interagiam uns com os outros", e também quando diz que "Duas aulas marcadas por trabalhos em dupla e o venezuelano sozinho". PE1 também relata esse fato em uma aula de Educação Física, quando escreve em seu caderno que:

\footnotetext{
Apesar do mesmo ficar isolado, sentado sozinho na arquibancada, com o gorro de sua blusa na cabeça, parece que se escondendo. Ele fica exaltado quando os meninos fazem gol, ou quando acontece algo engraçado com seus colegas, colocando as mãos na cabeça e pulando de emoção. Me pergunto: Como fazer com que ele se integre ao grupo? Até o momento, a única interação que o mesmo teve foi comigo no horário de Português! (PE1).
}

Outro fato que dificultava a convivência do aluno venezuelano com os estudantes brasileiros era o lugar em que se sentava na sala de aula. Como eles tinham um "mapa de sala", PE2 relatou diversas vezes em seu caderno de campo que "O aluno venezuelano se senta na primeira fila do lado direito da sala". O fato de se sentar à frente não é um problema, mas “[...] ele se torna excluído e sua interação com o restante da sala é dificultado" (PE2).

Curiosamente, ele se sentava na primeira carteira do lado direito e o aluno autista da sala sentava-se na primeira carteira do lado esquerdo. Além disso, nesse ambiente somente esses dois alunos de toda a classe eram deixados de lado, como informaram, respectivamente, PE1 e PE2: “[...] não pude perceber muita convivência dos alunos da sala com o aluno autista" $\mathrm{e}$ "[...] os únicos sozinhos eram o aluno autista, que possui uma acompanhante em sala de aula, mas que ainda não havia chegado, e o garoto venezuelano".

Gláuks: Revista de Letras e Artes-jan/jun. 2020 - Vol. 20, $N^{o} 1$ 
Relaciona-se esse fato com a notícia "Autista não: imigrante" publicada pelo Estadão $^{18}$. A reportagem conta vários casos de alunos imigrantes que foram tratados como autistas por não serem totalmente hábeis em português. Dentre eles, está o caso de uma menina síria que foi "diagnosticada" pela escola como autista, com déficit de atenção, dislexia e deficiência de aprendizagem. De acordo com o que se lê na reportagem:

Na Unidade Básica de saúde mais próxima, o caso de H. não foi novidade. Era 2015 e vigorava a "chuva de papeizinhos", nas palavras de quem trabalha na UBS, referindo-se à quantidade incomum de pedidos de avaliação psicológica a imigrantes - uma situação que se intensificou com o aumento do fluxo migratório ao País (BRANDALISE, 2017, p. 2).

Há também o caso de um menino de 7 anos, do Congo, o qual, como relatado na notícia:

[...] escondeu-se embaixo da carteira na sala de aula, em uma escola estadual da zona norte, e não quis mais sair. A professora ordenava, os colegas riam, todos os olhos nele. A situação repetiu-se algumas vezes, e a UBS do bairro recebeu um pedido: avaliar R., congolês que vivia em São Paulo havia um ano, por "sinais sugestivos de autismo" (BRANDALISE, 2017, p. 4).

Como na reportagem, PE2 relata um momento na sala de aula em que os alunos brasileiros debochavam justamente do aluno autista e posteriormente do venezuelano, quando ambos leram um texto em voz alta na sala de aula. Sobre esse fato, PE2 diz que "Além de debocharem do aluno, também se comportaram igualmente com a leitura do adolescente autista". O relatado nos demonstra como a falta de aceitação do outro compromete a convivência entre os alunos.

Se, por um lado, os dados apresentaram uma constante exclusão do aluno venezuelano, também desvelaram alguns indícios, mesmo que raros, de possíveis

\footnotetext{
${ }^{18}$ Disponível em https://educacao.estadao.com.br/noticias/geral,autista-nao-imigrante,70001705273. Acesso em $11 \mathrm{de}$ outubro de 2018.
}

Gláuks: Revista de Letras e Artes-jan/jun. 2020 -Vol. 20, $N^{o} 1$ 
convivências e relações interculturais entre ele e seus colegas de classe, como pode-se constatar a partir de algumas respostas positivas aos questionários e também a partir do caderno de campo, quando PE1 relata, por exemplo, que o aluno venezuelano "[...] interagiu um pouquinho com seu colega de trás, que [...] brincava com o grampeador e fingia que grampeava a orelha [...]. Segundo PE1, o aluno venezuelano "[...] achava essa atitude do colega muito engraçada".

PE1 ainda expõe, por meio de suas anotações, outros momentos marcados por esse pequeno contato em "As próximas duas aulas foram de matemática, todos os colegas da sala brincam com o ${ }^{* 19}$, já que o mesmo senta perto do ventilador. Os colegas iam e ligavam o ventilador e ele desligava, fizeram isso várias vezes, todos rindo muito".

PE2 também pode observar alguns momentos de convívio como quando escreveu que "No segundo horário, houve três momentos de interação" e como quando registrou que "Um aluno brasileiro ajudou o aluno imigrante a entender uma proposta de trabalho e, logo após, é chamado a fazer parte de um grupo entre meninas, onde, inicialmente, foi possível observar uma pequena resistência da parte dele, mas depois se entrosa com elas”. Ainda assim, apesar desses pequenos momentos de convívio, constatou-se que, na maior parte das vezes, o aluno venezuelano se encontrava isolado dos demais colegas de sala, percebendo-se pouco contato entre eles.

Pelo número de respostas negativas por parte dos estudantes brasileiros, percebe-se que, apesar de vivermos em um país extremamente miscigenado e de termos salas de aula plurais, não convivemos bem com as diferenças culturais, tampouco com alunos estrangeiros que possuem outra língua e outra cultura.

Além de apresentar dificuldades para se relacionar com os educadores e com os companheiros de sala, o estudante venezuelano não falava português, o que por vezes era entendido como "falta de interesse" em aprender a nova língua que se lhe apresentava como uma imposição. Goenechea (2008, p. 125) também discursa sobre isso quando relata as

${ }^{19}$ O nome do estudante foi omitido por razões éticas.

Gláuks: Revista de Letras e Artes-jan/jun. 2020 -Vol. 20, $N^{o} 1$ 
situações de imigração nas escolas espanholas: "Al parecer, hay una tendencia en el profesorado a relacionar la presencia de alumnos extranjeros con un problema [...]"20.

Em relação às respostas das professoras, pode-se perceber que as 3 profissionais que responderam ao questionário possuem perspectivas diferentes sobre a categoria "convivência". P1, em sua resposta à primeira pergunta - "Para você, como é conviver com um falante de espanhol na escola que não é fluente em português? Por quê?”, acredita que o processo de convívio é difícil, pois, segundo ela, "não conseguimos nos comunicar de forma clara”. Tal fato demonstra que a língua é a principal responsável pela integração e é fundamental para o estabelecimento das interrelações sociais, pois é por ela que dois ou mais indivíduos, a partir de uma convivência diária, trocarão experiências e conhecimentos.

Para P2, ainda sobre a mesma questão, a convivência com o aluno venezuelano é "Interessante, pois é possível conviver com culturas diferentes. O aluno de outro país nos motiva a conhecer novas culturas, aprender novas línguas, dentre outras". Já P3 relata essa experiência como "Desafiadora, pois os hábitos, cultura e maneira de tratar é diferente. Mas tem sido um bom aprendizado". Tais relatos demonstram um bom ponto de partida para ser um professor intercultural, haja vista que, apesar das dificuldades, as professoras percebem nessa convivência uma possibilidade de aprendizado.

Com as respostas à primeira pergunta do questionário, vê-se então, que das 3 professoras participantes, 2 relatam essa experiência de convivência de modo positivo, demonstrando princípios de interculturalidade. Porém, analisando as anotações nos cadernos de campo, percebem-se algumas divergências com os questionários, ainda que não se saiba se as professoras cujas aulas foram observadas são as mesmas que responderam aos questionários.

Segundo registros dos cadernos de campo, as aulas em que o aluno venezuelano mais interagia com algum professor eram as de um estagiário que atuava na escola, conforme se lê no seguinte trecho das anotações de PE1:

\footnotetext{
20 "Ao que parece, existe uma tendência por parte dos professores de relacionarem a presença de alunos estrangeiros como um problema".
}

Gláuks: Revista de Letras e Artes-jan/jun. 2020 -Vol. 20, $N^{o} 1$ 
No último horário, na aula de Ciências ministrada por um estagiário, foi a aula que ele mais interagiu, apesar de a professora da matéria (que também estava na sala de aula), ter dito que o venezuelano era muito resistente e não interagia muito. Porém, o professor-estagiário propôs uma atividade em grupo. Pelo que entendi, ele gosta muito da matéria, porque até respondeu algumas perguntas (PE1).

Vê-se a importância de dar ênfase ao fragmento acima porque, se as professoras têm essa proposta inclusiva, valorizando, portanto, a convivência, como relatam no questionário, não se espera que as anotações no caderno de campo difiram das respostas dadas por elas. PE1 também relata essa convivência com o estagiário no seguinte trecho: "No último horário, aula de ciências, ele participa muito da aula e conversa bastante com o estagiário que interage muito bem com ele".

Nas outras aulas, as pesquisadoras somente perceberam que o venezuelano ficava calado e não interagia com ninguém, nem com os alunos, nem com os professores, como afirma PE2 em suas observações: "Nota-se, então, alguns sinais de uma possível discriminação em sala de aula". Apoiando-nos em Freire (2011), salientamos que as discriminações de qualquer natureza devem ser combatidas dentro do ambiente escolar, tanto pelos educadores, quanto pelos educandos. Para o mestre:

[...] faz parte [...] do pensar certo a rejeição mais decidida a qualquer forma de discriminação. A prática preconceituosa de raça, de classe, de gênero ofende a substantividade do ser humano e nega radicalmente a democracia (FREIRE, 2011, p. 37).

Ainda, em uma posterior anotação de PE2, a pesquisadora relata que "Em uma interação entre os alunos na aula de laboratório, onde suas vozes se sobressaíam, a professora responsável pela turma chamou as atenções dos alunos, encarando na maioria das vezes o venezuelano". Recorrendo uma vez mais a Freire (2011, p. 52), sobre a intervenção do professor em sala de aula, lê-se: “[...] sei que as coisas podem até piorar, mas sei que é possível intervir para melhorá-las". Também o mesmo autor declara que:

Gláuks: Revista de Letras e Artes-jan/jun. 2020 -Vol. 20, $N^{o} 1$ 
O professor que desrespeita a curiosidade do educando, o seu gosto estético, a sua inquietude, a sua linguagem, mais precisamente, a sua sintaxe e a sua prosódia; o professor que ironiza o aluno, que o minimiza, que manda que "ele se ponha em seu lugar" ao mais tênue sinal de rebeldia legítima, tanto quanto o professor que se exime do cumprimento de seu dever de propor limites à liberdade do aluno, que se furta ao dever de ensinar, de estar respeitosamente presente à experiência formadora do educando, transgride os princípios fundamentalmente éticos de nossa existência (FREIRE, 2011, p. 52).

Ao analisar as respostas dos estudantes brasileiros juntamente com as das professoras e as observações feitas nos cadernos de campo das pesquisadoras, chega-se à conclusão de que a interculturalidade pode ser um meio de integração do aluno venezuelano no contexto escolar. Assim, é possível combater a idealização da sociedade homogênea, que dificulta a convivência e, portanto, a relação com o diferente. Ressaltamos que os questionários continham 4 perguntas cada um, no entanto, nem todas as perguntas apresentam pertinência para efeitos de análise da categoria "convivência".

Relatadas as implicações que foram percebidas nas análises dos dados a partir da interpretação dos questionários, comparativamente às anotações nos cadernos de campo e com base nos estudos teóricos realizados, e feitas breves reflexões acerca da imigração e da formação inicial do professor para essa realidade, passamos à seção final deste artigo.

\section{Considerações finais}

Neste artigo apresentamos parte dos resultados da pesquisa " $A$ escola viçosense e as experiências de imigração venezuelana: questões linguístico-culturais de uma nova demanda", desenvolvida em um projeto de Iniciação Científica na UFV. Retornando à pergunta de pesquisa, em que se buscou compreender como convivia e se intercomunicava um aluno venezuelano de uma escola municipal de Viçosa/MG, nas relações com os 
brasileiros em ambiente escolar e quais são as demandas de ações percebidas pela escola e pelos próprios estudantes para aperfeiçoar tais relações, várias considerações foram feitas em três categorias de análise: "convivência", "intercomunicação" e "demandas".

$\mathrm{Na}$ categoria "convivência", que nos interessou neste texto, identificamos que o estudante venezuelano parecia excluído na turma, dados os poucos momentos de convívio direto estabelecidos com os colegas de sala e com os professores, segundo observações dos cadernos de campo. Embora as professoras e os estudantes brasileiros revelassem existir uma interação entre todos, tal fato não se verificou permanentemente durante o período de acompanhamento de aulas pelas pesquisadoras.

A pesquisa aqui relatada proporcionou a estudantes de licenciatura da UFV discutir sobre imigração, experiência muito importante para as pesquisadoras participantes. E, a partir de tudo isso, logrou-se também a discussão sobre a identidade latino-americana. Percebeu-se o impacto positivo que este trabalho causou na comunidade escolar estudada, dado o interesse que despertou para a materialização das trocas linguísticas e culturais entre brasileiros e venezuelano, entre as pesquisadoras e os demais participantes da pesquisa.

Também veem-se, por meio do estudo apresentado, exemplos de abordagens inclusivas e interculturais que deram certo em outras escolas do país. Essas sugestões podem ser benéficas tanto para a escola onde foi feita a pesquisa, quanto para outras escolas que futuramente venham a receber demandas de estudantes estrangeiros que não falam a língua portuguesa, e que também provêm de outra cultura.

Finalmente, é importante ressaltar que este trabalho pode ser útil para os atuais e futuros professores. Na medida que se discute sobre temas como a interculturalidade, a importância dessa abordagem para a formação de professores e questões referentes à imigração, tem-se uma ótima ferramenta para o professor, pesquisador ou qualquer outro cidadão que queira se aprofundar sobre o assunto. 


\title{
Referências Bibliográficas
}

\begin{abstract}
ASSIS, Joziane Ferraz de. "Eu, caçadora de mim”. O percurso de formação de uma professora de espanhol. 2018. 212 f. Tese (Doutorado em Letras) - Instituto de Letras, Universidade Federal da Bahia, Salvador, Bahia, 2018.
\end{abstract}

BRANDALISE, Vitor Hugo. Autista não: imigrante. Estadão. São Paulo, 19 mar. 2017. Disponível em: $\quad<$ https://educacao.estadao.com.br/noticias/geral,autista-naoimigrante,70001705273>. Acesso em: 11 de outubro de 2018.

FREIRE, Paulo. Pedagogia da Autonomia: Saberes necessários à prática educativa. 43. ed. São Paulo: Paz e Terra, 2011. 142 p.

GOENECHEA, Cristina Permisán. Análisis de la presencia de la cultura de origen de los menores inmigrantes en el sistema educativo andaluz. Congreso Internacional Infancia en Contextos de Riesgo. Huelva/Espanha, p. 1066-1075, 2014.

GOENECHEA, Cristina Permisán. ¿Es la formación del profesorado la clave de la educación intercultural? Revista Española de Pedagogia. Madrid: Universidad Internacional de La Rioja, v. LXVI, n. 239, p. 119-136, janeiro/abril, 2008.

PARAQUETT, Marcia. Multiculturalismo, interculturalismo e ensino/aprendizagem de espanhol para brasileiros. In: BRASIL. Ministério da Educação, Secretaria de Educação Básica. Espanhol. Ensino médio. Brasília: Ministério da Educação/Secretaria de Educação Básica, 2010. 292p. p. 137-156. (Coleção Explorando o Ensino).re

\section{La inmigración en clase: un análisis de la convivencia entre diferentes}

Resumen: El presente artículo es parte de una investigación de Iniciación Científica financiada por el Conselho Nacional de Desenvolvimento Científico e Tecnológico (CNPQ) por medio del Programa PIBIC/UFV ${ }^{21}$, y buscó analizar, a partir de la perspectiva intercultural, como se dieron la convivencia y los intercambios lingüísticos y culturales entre un alumno venezolano y sus compañeros de clase y profesores en una escuela de la ciudad de

${ }^{21}$ Agradecemos al CNPQ por la financiación de la investigación.

Gláuks: Revista de Letras e Artes-jan/jun. 2020 - Vol. 20, $N^{o} 1$ 
Viçosa/Minas Gerais. Para eso, se hizo un extenso estudio teórico, basado en autores como Assis (2018), Freire (2011), Paraquett (2010) y Goenechea (2008), se observó la realidad escolar con apuntes en cuadernos de campo y se hizo una aplicación de cuestionarios tanto al alumno venezolano como a sus compañeros de clase y profesores brasileños, tratándose, por lo tanto, de una investigación cualitativa, descriptiva e interpretativista. A partir del análisis de los datos, se identificó una constante exclusión del alumno extranjero, ya que los brasileños poco se comunicaban con él, así como la dificultad de las profesoras participantes de actuar en diferentes situaciones que presenta ese contexto. En el presente artículo presentaremos los resultados de la investigación en la categoría de análisis "convivencia", reflexionando sobre la inmigración, la presencia de alumnos extranjeros en clase y la formación del profesorado.

Palabras Clave: Interculturalidad, inmigración, profesorado, español lengua extranjera. 